\title{
Stability or improvement in forced vital capacity with nintedanib in patients with idiopathic pulmonary fibrosis
}

\author{
Kevin R. Flaherty ${ }^{1}$, Martin Kolb ${ }^{2}$, Carlo Vancheri ${ }^{3}$, Wenbo Tang ${ }^{4}$, \\ Craig S. Conoscenti ${ }^{4}$ and Luca Richeldi ${ }^{5}$
}

Affiliations: ${ }^{1}$ University of Michigan Health System, Ann Arbor, MI, USA. ${ }^{2}$ McMaster University, Hamilton, ON, Canada. ${ }^{3}$ Dept of Clinical and Experimental Medicine, University of Catania, Catania, Italy. ${ }^{4}$ Boehringer Ingelheim Pharmaceuticals, Inc., Ridgefield, CT, USA. ${ }^{5}$ Università Cattolica del Sacro Cuore, Fondazione Policlinico A. Gemelli, Rome, Italy.

Correspondence: Kevin R. Flaherty, University of Michigan Health System, Pulmonary and Internal Medicine, 3916 Taubman Center, 1500 East Medical Center Drive, Ann Arbor, Michigan, 48109-5360, USA. E-mail: flahertylamed.umich.edu

@ERSpublications

$25 \%$ of nintedanib-treated and $9 \%$ of placebo-treated patients in INPULSIS had an improvement in FVC over 52 weeks http://ow.ly/P30b30knPe2

Cite this article as: Flaherty KR, Kolb M, Vancheri C, et al. Stability or improvement in forced vital capacity with nintedanib in patients with idiopathic pulmonary fibrosis. Eur Respir J 2018; 52: 1702593 [https://doi.org/10.1183/13993003.02593-2017].

ABSTRACT In the Phase III INPULSIS ${ }^{\circledast}$ trials, nintedanib reduced the annual rate of decline in forced vital capacity (FVC) versus placebo in patients with idiopathic pulmonary fibrosis (IPF).

We conducted post hoc analyses of the distribution of changes in FVC in the INPULSIS ${ }^{\star}$ trials and FVC changes in the open-label extension trial INPULSIS ${ }^{\circ}-\mathrm{ON}$ in subgroups of patients based on whether patients had shown an improvement or no decline in FVC in INPULSIS ${ }^{\oplus}$. Analyses were descriptive.

Based on the annual rate of change in FVC, 158 of 638 patients (24.8\%) treated with nintedanib and 38 of 423 patients $(9.0 \%)$ treated with placebo had an improvement/no decline in FVC in the INPULSIS ${ }^{\circ}$ trials. In patients whose FVC improved/did not decline, median (interquartile range) improvements in FVC at week 52 were $76.5(31-152) \mathrm{mL}$ and $57.5(31-103) \mathrm{mL}$ in the nintedanib and placebo groups, respectively. Changes in FVC from baseline to week 48 of INPULSIS ${ }^{\oplus}$-ON were similar in patients whose FVC improved or declined in the preceding INPULSIS ${ }^{\oplus}$ trial.

In the INPULSIS ${ }^{\star}$ trials, treatment with nintedanib resulted in a greater proportion of patients with IPF showing an improvement/no decline in FVC compared to taking placebo. Mechanisms underlying improvement in FVC in patients with IPF are unknown. 


\section{Introduction}

Idiopathic pulmonary fibrosis (IPF) is a chronic interstitial lung disease characterised by a progressive decline in lung function [1]. The clinical course of IPF is variable and unpredictable, with some patients declining rapidly, others progressing much more slowly, and some experiencing periods of relative stability punctuated by episodes of acute respiratory decline [2]. In the absence of therapies that can halt fibrosis, the goal of IPF treatment is to slow disease progression by reducing the decline in lung function [3]. A decline in forced vital capacity (FVC) is recognised as a clinically relevant measure of disease progression in patients with IPF $[4,5]$.

Nintedanib is an intracellular inhibitor of tyrosine kinases that inhibits processes fundamental to the pathogenesis of IPF, including the proliferation, migration and differentiation of fibroblasts, and the deposition of extracellular matrix (ECM), as well as having anti-inflammatory effects [6]. The efficacy and safety of 52 weeks' treatment with nintedanib $150 \mathrm{mg}$ twice daily in patients with IPF were assessed in two replicate Phase III INPULSIS ${ }^{\infty}$ trials. In both trials, nintedanib significantly reduced the annual rate of decline in FVC compared with placebo ( -113.6 versus $-223.5 \mathrm{~mL} \cdot y e a r^{-1}$ based on pooled data) [7]. A significantly smaller proportion of the patients treated with nintedanib versus placebo had a decline in FVC $\geqslant 5 \%$ pred $(47 \%$ versus $61 \%)$ or $\geqslant 10 \%$ pred $(30 \%$ versus $39 \%)$ from baseline to week 52 [8]. These thresholds of decline in FVC over 6-12 months have been shown to be predictive of mortality in patients with IPF $[9,10]$. Patients who completed the INPULSIS ${ }^{\oplus}$ trials were eligible to enter an open-label extension trial known as INPULSIS ${ }^{\circledR}$-ON. Results from an interim analysis of data from INPULSIS ${ }^{\bullet}$-ON suggest that the effect of nintedanib on reducing disease progression is maintained over long-term treatment [11].

We present the results of a post hoc analysis of the distribution of changes in FVC in the INPULSIS ${ }^{\star}$ trials and the average changes in FVC in patients whose FVC improved or did not decline (i.e. who had no change or no increase in FVC) in the INPULSIS ${ }^{\circ}$ trials. In addition, we describe the changes in FVC in INPULSIS $^{\oplus}$-ON in subgroups of patients grouped according to whether or not they had shown an improvement/no decline in FVC in the INPULSIS ${ }^{\circledast}$ trials.

\section{Materials and methods}

The design of the INPULSIS ${ }^{ø}$ trials has been described [7]. Briefly, patients with a diagnosis of IPF within the previous 5 years, FVC $\geqslant 50 \%$ pred, forced expiratory volume in $1 \mathrm{~s} / \mathrm{FVC}$ ratio $\geqslant 0.7$ and diffusing capacity of the lung for carbon monoxide (DLCO) 30-79\% pred were enrolled. In the absence of a surgical lung biopsy, patients had to have a high-resolution computed tomography (HRCT) scan showing honeycombing or a combination of traction bronchiectasis and reticulation in the absence of atypical features of usual interstitial pneumonia (UIP). Patients were randomised (3:2) to receive nintedanib $150 \mathrm{mg}$ twice daily or placebo for 52 weeks, with a follow-up visit 4 weeks later. Patients who completed the 52-week treatment period and follow-up visit were eligible to enter the open-label extension trial, INPULSIS ${ }^{\oplus}$-ON. In both INPULSIS ${ }^{\circledR}$ and INPULSIS ${ }^{\circledR}$-ON, dose reductions and treatment interruptions were permitted to manage adverse events. The protocols for both trials were approved by an ethics committee or institutional review board at every participating centre, and informed consent was obtained from all participants.

In the INPULSIS ${ }^{\oplus}$ trials, FVC was measured at baseline, at weeks 2, 4, 6, 12, 24, 36 and 52, and at the follow-up visit. Patients who prematurely discontinued trial medication were encouraged to attend all visits as originally planned. In INPULSIS ${ }^{\oplus}$-ON, FVC was measured at baseline, at weeks $2,4,6,12,24,36$ and 48 , and then every 16 weeks. Spirometry was conducted using sponsor-provided machines and according to criteria provided by the American Thoracic Society and European Respiratory Society [12].

The annual rate of change in FVC in the INPULSIS ${ }^{\star}$ trials was analysed using a random coefficient regression model with fixed effects for sex, age, height and random effect of patient-specific intercept and time. All available FVC values from baseline to week 52 were used, including FVC measurements from the follow-up visit for patients who prematurely discontinued trial medication and did not complete study visits until week 52. The St George's Respiratory Questionnaire (SGRQ) [13] was used to assess health-related quality of life at baseline and at weeks $6,12,24$ and 52 of the INPULSIS ${ }^{\circledR}$ trials.

Adverse events were documented according to preferred terms in the Medical Dictionary for Regulatory Activities (MedDRA). Weight loss was recorded based on adverse events coded using the preferred term "weight decrease" in the MedDRA.

The following descriptive analyses were conducted post hoc based on pooled data from both INPULSIS ${ }^{\circledR}$ trials: distribution of annual rate of change in $\mathrm{FVC}\left(\mathrm{mL} \cdot \mathrm{year}^{-\mathbf{1}}\right)$ in the nintedanib and placebo groups in patients treated with $\geqslant 1$ dose of study medication; change from baseline in FVC $(\mathrm{mL})$ at week 52 in the nintedanib and placebo groups in patients whose FVC improved/did not decline based on the annual rate 
of change in patients treated with $\geqslant 1$ dose of study medication; change from baseline in SGRQ total score at week 52 in the nintedanib and placebo groups in patients whose FVC improved/did not decline and in patients whose FVC declined based on the annual rate of change in FVC in patients treated with $\geqslant 1$ dose of study medication; proportion of patients who had weight loss at week 52 in the nintedanib and placebo groups in patients whose FVC improved/did not decline and in patients whose FVC declined based on the annual rate of change in FVC in patients treated with $\geqslant 1$ dose of study medication; distributions of change from baseline in FVC ( $\mathrm{mL}$ and \% pred) at week 52 in the nintedanib and placebo groups in patients who had an FVC value at week 52; and change from baseline in FVC ( $\mathrm{mL}$ and \% pred) at week 52 in the nintedanib and placebo groups in patients whose FVC improved/did not decline based on their FVC value at week 52. Analyses of change from baseline in FVC ( $\mathrm{mL}$ and \% pred) at week 52 in patients whose FVC improved/did not decline based on their FVC value at week 52 were repeated excluding patients whose FVC values improved by $>800 \mathrm{~mL}$ (outliers) as these were likely to be false readings.

The following descriptive analyses were conducted post hoc based on data from INPULSIS ${ }^{\oplus}$-ON: change in FVC $(\mathrm{mL})$ from baseline of INPULSIS ${ }^{-}$-ON at weeks $2,4,6,12,24,36$ and 48 of INPULSIS ${ }^{\circledR}$-ON in subgroups of patients whose FVC improved/did not decline or declined in INPULSIS ${ }^{\infty}$ based on the annual rate of change in patients treated with $\geqslant 1$ dose of study medication in INPULSIS . $^{\star}$

FVC \% pred was calculated using the following equations [14]: for males, FVC predicted $(\mathrm{L})=5.76 \times$ height (metres) $-0.026 \times$ age (years) -4.34 ; for females, FVC predicted $(\mathrm{L})=4.43 \times$ height (metres) $-0.026 \times$ age (years) -2.89 .

\section{Results}

\section{Patients}

A total of 1061 patients were treated in the INPULSIS ${ }^{\bullet}$ trials (638 with nintedanib, 423 with placebo). Of 807 patients who completed an INPULSIS ${ }^{\oplus}$ trial, 734 patients (91\%) were treated in INPULSIS ${ }^{\circ}$-ON: 430 continued nintedanib (having taken nintedanib in INPULSIS ${ }^{\circledR}$ ) and 304 started taking nintedanib (having taken placebo in INPULSIS ${ }^{\circledR}$.

\section{Improvement in FVC based on annual rate of change in FVC in INPULSIS ${ }^{\circledR}$}

The distributions of the annual rate of change in FVC $\left(\mathrm{mL} \cdot \mathrm{year}^{-1}\right)$ in the nintedanib and placebo groups are presented in figure 1 and supplementary figure S1. Patients indicated by the bars on the left side of the graph are those whose FVC declined the most; patients indicated by the bars on the right side of the graph are those whose FVC improved the most. The distribution of the annual rate of change in FVC is further to the right in patients treated with nintedanib than placebo. Based on the annual rate of change in FVC $\left(\mathrm{mL} \cdot \mathrm{year}^{-1}\right), 158$ of 638 patients $(24.8 \%)$ in the nintedanib group and 38 of 423 patients $(9.0 \%)$ in the placebo group had an improvement or no decline (no change) in FVC. In patients whose FVC improved/ did not decline based on the annual rate of change, median (interquartile range) improvements in FVC at week 52 were $76.5(31-152) \mathrm{mL}$ in the nintedanib group and 57.5 (31-103) $\mathrm{mL}$ in the placebo group.

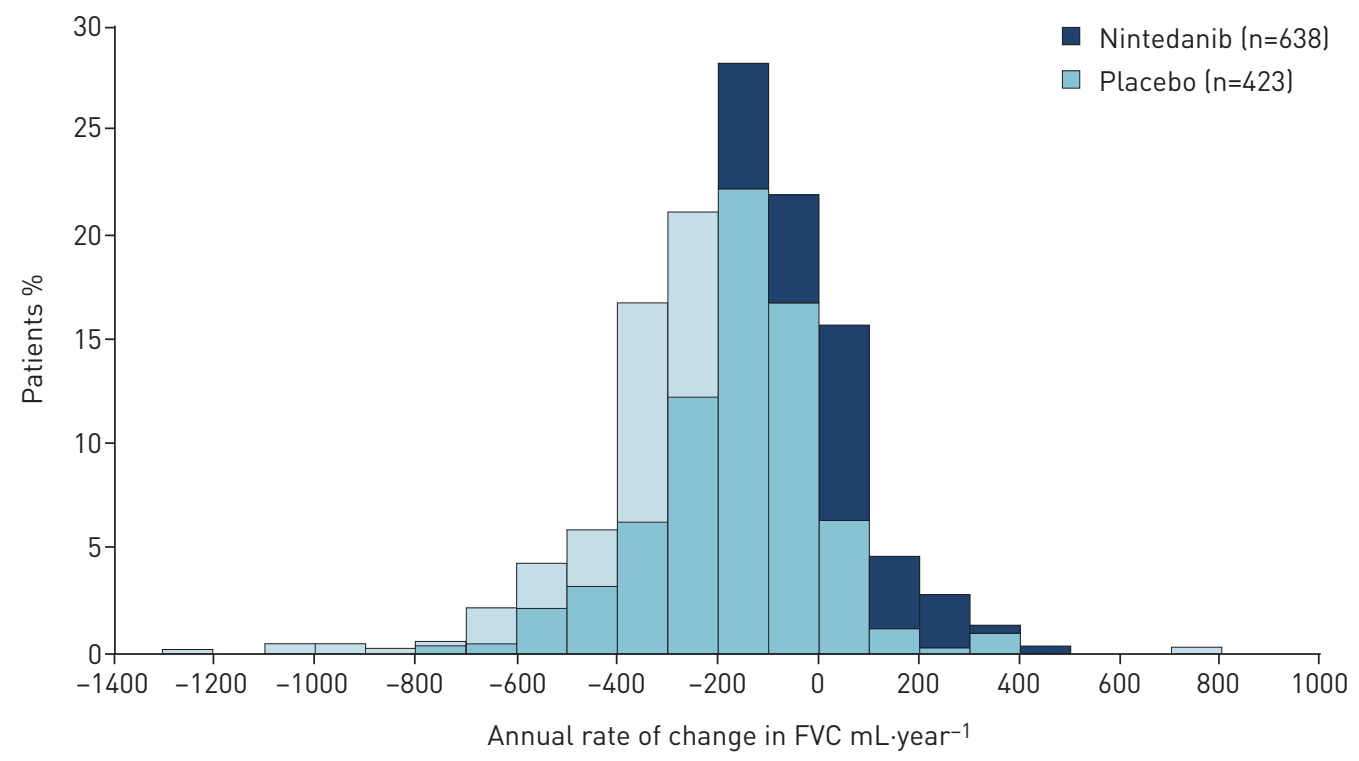

FIGURE 1 Annual rate of change in forced vital capacity (FVC) in the INPULSIS ${ }^{\circledR}$ trials. 
Baseline characteristics including age, sex, weight, FVC and presence of honeycombing on HRCT were generally similar between patients whose FVC improved/did not decline in INPULSIS ${ }^{\circledR}$ and patients whose FVC declined based on the annual rate of change in FVC (table 1; supplementary figures S2-5).

Improvement in FVC based on change from baseline in FVC in INPULSIS ${ }^{8}$

In total, 864 of the treated patients $(81.4 \%)$ had an FVC value at week 52 (519 treated with nintedanib, 345 with placebo). The distribution of changes in FVC (mL) in the nintedanib and placebo groups in patients with an FVC value at week 52 is presented in supplementary figure S6. Based on change from baseline in FVC $(\mathrm{mL})$ at week 52, 191 patients $(36.8 \%)$ in the nintedanib group had an improvement/no decline in FVC (of whom 181 had an improvement) and 62 patients (18.0\%) in the placebo group had an improvement/no decline in FVC (of whom 55 had an improvement). Three outliers in the placebo group had a change from baseline in FVC at week 52 of $>800 \mathrm{~mL}(883 \mathrm{~mL}$, $1267 \mathrm{~mL}, 1578 \mathrm{~mL}$ ).

In patients whose FVC improved/did not decline based on change from baseline in FVC (mL), median (interquartile range) improvements in FVC at week 52 were $110(47-227) \mathrm{mL}$ in the nintedanib group and $105(39-175) \mathrm{mL}$ in the placebo group (or $98(39-169) \mathrm{mL}$ if the three outliers with increases in FVC $>800 \mathrm{~mL}$ were excluded).

The distribution of mean changes in FVC \% pred in the nintedanib and placebo groups in patients with an FVC value at week 52 is presented in supplementary figure S7. In patients whose FVC improved/did not decline based on change from baseline in FVC $(\mathrm{mL})$, median (interquartile range) improvements in FVC \% pred at week 52 were 3.3 (1.6-6.7) \% pred in the nintedanib group and $3.2(1.4-5.0) \%$ pred in the placebo group (or 3.0 (1.4-4.9) \% pred if the three outliers with increases $>800 \mathrm{~mL}$ were excluded).

\section{Changes in SGRQ}

In patients whose FVC improved/did not decline based on the annual rate of change, mean \pm SD change from baseline in SGRQ total score at week 52 was $-1.9 \pm 13.5$ and $-1.9 \pm 17.6$ in the nintedanib and placebo groups, respectively. In patients whose FVC declined based on the annual rate of change, mean \pm SD change from baseline in SGRQ total score at week 52 was $4.9 \pm 16.0$ and $5.2 \pm 15.4$ in the nintedanib and placebo groups, respectively.

\begin{tabular}{|c|c|c|c|c|}
\hline & \multicolumn{2}{|c|}{$\begin{array}{l}\text { Improvement or no } \\
\text { decline in FVC }\end{array}$} & \multicolumn{2}{|c|}{ Decline in FVC } \\
\hline & Nintedanib & Placebo & Nintedanib & Placebo \\
\hline Subjects $\mathrm{n}$ & 158 & 38 & 480 & 385 \\
\hline Age years & $66.3 \pm 7.9$ & $67.6 \pm 8.2$ & $66.7 \pm 8.2$ & $66.9 \pm 7.9$ \\
\hline Male & 126 (79.7) & 31 (81.6) & $381(79.4)$ & 303 (78.7) \\
\hline \multicolumn{5}{|l|}{ Race } \\
\hline White & 99 (62.7) & 24 (63.2) & $261(54.4)$ & $224(58.2)$ \\
\hline Black & $1(0.6)$ & $0(0.0)$ & $1(0.2)$ & $0(0.0)$ \\
\hline Asian & $38(24.1)$ & $11(28.9)$ & 156 (32.5) & $117(30.4)$ \\
\hline Missing ${ }^{\#}$ & $20(12.7)$ & $3(7.9)$ & $62(12.9)$ & $44(11.4)$ \\
\hline Former or current smoker & $130(82.3)$ & $28(73.7)$ & $334(69.6)$ & 273 (70.9) \\
\hline Weight kg & $82.6 \pm 15.4$ & $83.9 \pm 18.0$ & $78.1 \pm 16.8$ & $78.1 \pm 16.3$ \\
\hline Time since diagnosis of IPF years & $1.6 \pm 1.4$ & $1.5 \pm 1.1$ & $1.7 \pm 1.4$ & $1.6 \pm 1.3$ \\
\hline FVC mL & $2850 \pm 782$ & $2949 \pm 827$ & $2669 \pm 744$ & $2706 \pm 806$ \\
\hline FVC \% pred & $81.6 \pm 18.1$ & $84.4 \pm 19.8$ & $79.1 \pm 17.4$ & $78.8 \pm 18.0$ \\
\hline D.co \% pred & $47.5 \pm 12.3$ & $50.7 \pm 17.1$ & $47.4 \pm 13.9$ & $46.6 \pm 12.9$ \\
\hline \multicolumn{5}{|l|}{ Diagnostic subgroup } \\
\hline No honeycombing on HRCT and no biopsy & 50 (31.7) & $8(21.1)$ & $163(34.0)$ & $117(30.4)$ \\
\hline $\begin{array}{l}\text { Honeycombing on HRCT and/or confirmation of UIP } \\
\text { by biopsy }\end{array}$ & $108(68.4)$ & $30(79.0)$ & $317(66.0)$ & $268(69.6)$ \\
\hline
\end{tabular}

Data are presented as mean \pm SD or $\mathrm{n}(\%)$, unless otherwise stated. FVC: forced vital capacity; IPF: idiopathic pulmonary fibrosis; DLCO: diffusing capacity of the lung for carbon monoxide; HRCT: high-resolution computed tomography; UIP: usual interstitial pneumonia. "\#: in France, regulations did not permit the collection of data on race. 


\section{Weight loss}

In patients whose FVC improved/did not decline based on the annual rate of change, 17 patients $(10.8 \%)$ and 2 patients $(5.3 \%)$ in the nintedanib and placebo groups, respectively, had weight loss at week 52 . In patients whose FVC declined based on the annual rate of change, 45 patients (9.4\%) and 13 patients (3.4\%) in these groups, respectively, had weight loss at week 52.

\section{INPULSIS ${ }^{\circledR}-$ ON}

In patients treated with nintedanib in INPULSIS ${ }^{\circledR}$ whose FVC improved/did not decline in INPULSIS ${ }^{\circledR}$ based on the annual rate of change in FVC $(n=158)$, mean \pm SD change in FVC from baseline at week 48 of INPULSIS $^{\oplus}$-ON was $-70 \pm 246 \mathrm{~mL}$ (table 2). In patients treated with nintedanib in INPULSIS ${ }^{\bullet}$ whose FVC declined in INPULSIS ${ }^{\infty}$ based on the annual rate of change in FVC $(n=480)$, mean \pm SD change in FVC from baseline at week 48 of INPULSIS ${ }^{\circledR}$-ON was $-110 \pm 231 \mathrm{~mL}$.

In patients treated with placebo in INPULSIS ${ }^{\circledR}$ whose FVC improved/did not decline in INPULSIS ${ }^{\circledR}$ based on the annual rate of change in FVC $(n=38)$, mean \pm SD FVC change from baseline at week 48 of INPULSIS $^{\circ}$-ON was $-45 \pm 226 \mathrm{~mL}$. In patients treated with placebo in INPULSIS ${ }^{\oplus}$ whose FVC declined in INPULSIS $^{\infty}$ based on the annual rate of change in FVC $(n=385)$, mean \pm SD FVC change from baseline at week 48 of INPULSIS ${ }^{\oplus}$-ON was $-76 \pm 246 \mathrm{~mL}$.

\section{Discussion}

Based on pooled data on the annual rate of change in FVC in the two INPULSIS ${ }^{\oplus}$ trials, treatment with nintedanib resulted in a greater proportion of patients showing an improvement/no decline in FVC over 52 weeks of treatment compared with taking placebo ( $24.8 \%$ versus $9.0 \%)$. Among patients whose FVC improved/did not decline, the median improvement in FVC was approximately $77 \mathrm{~mL}$ in the nintedanib group and $58 \mathrm{~mL}$ in the placebo group. Although spirometric measurements are subject to a small degree of error [12], it is clear from the distribution of changes in FVC that in some patients the improvements in FVC were larger than could be explained by errors in measurement.

None of the baseline characteristics that we studied were predictive of improvement in FVC over the course of the INPULSIS ${ }^{\circ}$ trials. This finding is in line with previous subgroup analyses of the INPULSIS trials showing that the treatment effect of nintedanib on FVC is consistent across subgroups defined by baseline characteristics including FVC \% pred [15, 16], DLCO \% pred [17], diagnostic criteria (features of possible UIP with traction bronchiectasis on HRCT versus honeycombing on HRCT and/or confirmation of UIP by surgical lung biopsy) [18], presence/absence of honeycombing on HRCT [19] and presence/ absence of emphysema [20]. IPF is a complex and heterogeneous disease that has an unpredictable clinical course $[2,21-23]$. Thus it should perhaps not be surprising that these analyses did not identify baseline

TABLE 2 Change in FVC (mL) from baseline of INPULSIS ${ }^{\circledR}-\mathrm{ON}$ at week 48 in patients whose FVC improved or did not decline in INPULSIS ${ }^{\circledR}$ and in patients whose FVC declined in INPULSIS ${ }^{\circledR}$ (based on the annual rate of change in INPULSIS ${ }^{\circledR}$ )

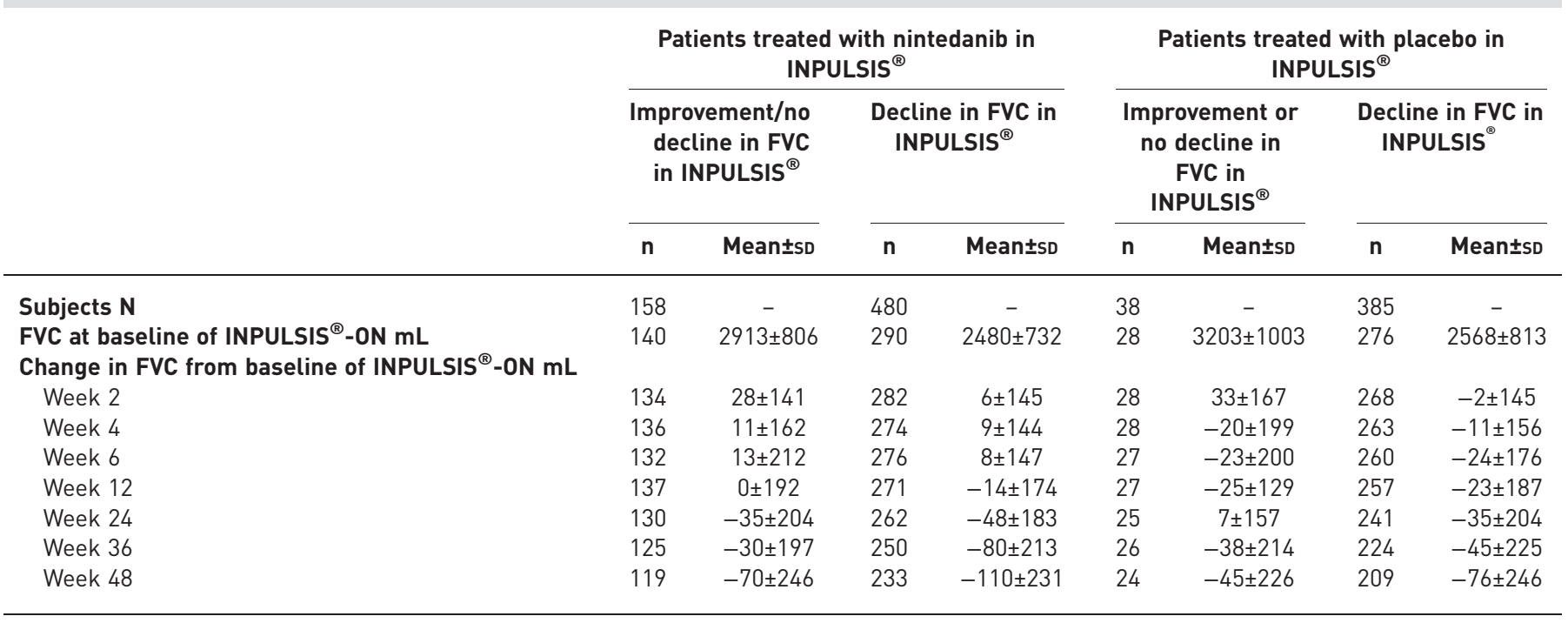

FVC: forced vital capacity. ${ }^{\#}$ : all patients were treated with open-label nintedanib in INPULSIS ${ }^{\circledR}-$ ON. 
characteristics that were predictive of an improvement in FVC. Changes in FVC from baseline to week 48 of the extension trial INPULSIS ${ }^{\oplus}$-ON were similar between patients whose FVC improved and patients whose FVC declined in the preceding INPULSIS ${ }^{\circledR}$ trial. This is consistent with previous studies showing that a decline in FVC is a poor predictor of future FVC decline, including an analysis of data from the INPULSIS $^{\infty}$ trials showing that change in FVC \% pred in the first 24 weeks did not predict FVC decline in the following 24 weeks [24]. It should be acknowledged, however, that studies showing that FVC decline is a poor predictor of FVC decline may be confounded by infrequent measurement and the occurrence of acute exacerbations. Studies in which FVC has been measured daily or weekly provide a more accurate picture of disease behaviour and have demonstrated a largely linear decline in FVC over 12 months in patients with IPF $[25,26]$.

There is some evidence to suggest that the SGRQ total score is sensitive to detecting change in patients with IPF whose FVC \% pred declines or improves [27-30]. In our study, patients whose FVC improved/ did not decline in INPULSIS ${ }^{\circledast}$ had a decrease (improvement) in SGRQ total score $(-1.9$ points in each treatment group) whereas patients whose FVC declined had an increase (worsening) in SGRQ total score (4.9 points in the nintedanib group and 5.2 points in the placebo group). The minimal clinically important difference of the SGRQ total score in patients with IPF has been estimated to be between 4 and 10 points $[27,30]$. The difference in change in SGRQ score between patients whose FVC improved and whose FVC declined might, therefore, reflect a clinically relevant difference in change in health-related quality of life between these groups of patients. Further analyses of data from the INPULSIS ${ }^{\oplus}$ trials have shown that stability/improvement in FVC over 52 weeks is associated with improvement in scores on other patient-reported outcomes, including the Cough and Sputum Assessment Questionnaire cough domains and EQ-5D visual analogue scale [31].

The observation that a minority of patients with IPF showed an improvement in FVC over the 52 weeks of the INPULSIS ${ }^{\oplus}$ trials challenges the concept that FVC can only decline in patients with IPF, although ultimately the disease will progress and lead to death in all patients. It should be noted that there was a mean decline in FVC in INPULSIS ${ }^{-}$-ON in the subgroup of patients whose FVC improved/did not decline in the preceding INPULSIS ${ }^{\star}$ trial. Treatment with nintedanib increased the likelihood of a patient showing an improvement in FVC. The mechanism(s) by which nintedanib might lead to an improvement in FVC is unknown. Nintedanib has been shown to reduce the secretion of ECM and upregulate matrix metalloproteinases that degrade the ECM $[6,32]$. Thus, in regions of the fibrotic lung that have not been decellularised and in which there is still turnover of ECM, i.e. both deposition and degradation, it may be hypothesised that nintedanib treatment leads to a net reduction in excess ECM, resulting in improved lung function. Further, recently published data from a mouse model of pulmonary fibrosis showed that short-term nintedanib treatment not only reduced lung fibrosis and vascular proliferation, but also essentially normalised the distorted microvascular architecture [33], suggesting that a restoration of alveolar structures may contribute to improved lung function in some patients treated with nintedanib. Further research is needed to elucidate the mechanisms by which FVC might be improved in patients with IPF.

These analyses have some limitations. As post hoc analyses, they should be regarded as exploratory. Not all patients had an FVC value at week 52. The INPULSIS-ON trial lacked a placebo comparator and is subject to bias in the population who completed an INPULSIS ${ }^{\circ}$ trial and so were eligible to participate.

In conclusion, in a post hoc analysis of pooled data from the INPULSIS ${ }^{\varpi}$ trials, treatment with nintedanib resulted in a greater proportion of patients with IPF showing an improvement/no decline in FVC compared to taking placebo over 52 weeks. No baseline characteristics were identified that predicted an improvement in FVC. The mechanisms behind improvement in FVC in patients treated with nintedanib are unknown.

Acknowledgements: Writing support was provided by Julie Fleming and Wendy Morris of FleishmanHillard Fishburn, London, UK, which was contracted and funded by Boehringer Ingelheim Pharmaceuticals, Inc. Boehringer Ingelheim was given the opportunity to review the manuscript for medical and scientific accuracy as well as intellectual property considerations. The authors received no direct compensation related to the development of the manuscript.

Conflict of interest: K.R. Flaherty reports grants and personal fees for consultancy from Boehringer Ingelheim and Roche/Genentech; personal fees for consultancy from Veracyte, Biogen, Aeolus, Pharmakea, Fibrogen and Sanofi-Genzyme; and grants from Afferent; outside the submitted work. M. Kolb reports grants from Canadian Pulmonary Fibrosis Foundation and Canadian Institute for Health Research; grants and personal fees for advisory board work from Pulmonary Fibrosis Foundation, Roche Canada and Janssen; personal fees for advisory board work from Boehringer Ingelheim, GlaxoSmithKline, AstraZeneca, Vertex, Genoa, Gilead, Prometic and Alkermes; and has been site principal investigator in industry-sponsored clinical trials for Roche, Sanofi and Boehringer Ingelheim; outside the submitted work. C. Vancheri reports grants and personal fees from Roche and Boehringer Ingelheim, outside the submitted work. W. Tang is an employee of Boehringer Ingelheim Pharmaceuticals, Inc. C.S. Conoscenti is an employee of Boehringer Ingelheim Pharmaceuticals, Inc. L. Richeldi reports grants and personal fees for advisory board work 
from InterMune; personal fees for advisory board work from Medimmune, Roche and Takeda; personal fees for consultancy from Biogen-Idec, Sanofi-Aventis and ImmuneWorks; personal fees for lecturing from Shionogi; personal fees for steering committee work from Boehringer Ingelheim; and personal fees from Pliant Therapeutics; outside the submitted work.

Support statement: The INPULSIS ${ }^{\circledR}$ and INPULSIS ${ }^{\circ}$-ON trials were funded by Boehringer Ingelheim Pharmaceuticals, Inc. Funding information for this article has been deposited with the Crossref Funder Registry.

\section{References}

1 Raghu G, Collard HR, Egan JJ, et al. An official ATS/ERS/JRS/ALAT statement: Idiopathic pulmonary fibrosis: evidence-based guidelines for diagnosis and management. Am J Respir Crit Care Med 2011; 183: 788-824.

2 Ley B, Collard HR, King TE Jr. Clinical course and prediction of survival in idiopathic pulmonary fibrosis. Am J Respir Crit Care Med 2011; 183: 431-440.

3 Travis WD, Costabel U, Hansell DM, et al. An official American Thoracic Society/European Respiratory Society statement: Update of the international multidisciplinary classification of the idiopathic interstitial pneumonias. Am J Respir Crit Care Med 2013; 188: 733-748.

4 du Bois RM, Nathan SD, Richeldi L, et al. Idiopathic pulmonary fibrosis: lung function is a clinically meaningful endpoint for phase III trials. Am J Respir Crit Care Med 2012; 186: 712-715.

5 Paterniti MO, Bi Y, Rekić D, et al. Acute exacerbation and decline in forced vital capacity are associated with increased mortality in idiopathic pulmonary fibrosis. Ann Am Thorac Soc 2017; 14: 1395-1402.

6 Wollin L, Wex E, Pautsch A, et al. Mode of action of nintedanib in the treatment of idiopathic pulmonary fibrosis. Eur Respir J 2015; 45: 1434-1445.

7 Richeldi L, du Bois RM, Raghu G, et al. Efficacy and safety of nintedanib in idiopathic pulmonary fibrosis. $N$ Engl J Med 2014; 370: 2071-2082.

8 Flaherty KR, Brown KK, Costabel U, et al. Cumulative distribution of patients by change in FVC \% predicted in the INPULSIS trials of nintedanib in patients with idiopathic pulmonary fibrosis. Am J Respir Crit Care Med 2016; 193: A2705.

9 Zappala CJ, Latsi PI, Nicholson AG, et al. Marginal decline in forced vital capacity is associated with a poor outcome in idiopathic pulmonary fibrosis. Eur Respir J 2010; 35: 830-836.

10 du Bois RM, Weycker D, Albera C, et al. Forced vital capacity in patients with idiopathic pulmonary fibrosis: test properties and minimal clinically important difference. Am J Respir Crit Care Med 2011; 184: 1382-1389.

11 Crestani B, Quaresma M, Kaye M, et al. Long-term nintedanib treatment in idiopathic pulmonary fibrosis (IPF): new data from INPULSIS-ON. Eur Respir J 2005; 50: Suppl. 61, OA3402.

12 Miller MR, Hankinson J, Brusasco V, et al. Standardisation of spirometry. Eur Respir J 2005; 26: 319-338.

13 Jones PW, Quirk FH, Baveystock CM. The St George's Respiratory Questionnaire. Respir Med 1991; 85: Suppl. B, 25-31.

14 Quanjer PH, Tammeling GJ, Cotes JE, et al. Lung volumes and forced ventilatory flows. Eur Respir J 1993; 6: Suppl. 16, 5-40.

15 Costabel U, Inoue Y, Richeldi L, et al. Efficacy of nintedanib in idiopathic pulmonary fibrosis across prespecified subgroups in INPULSIS. Am J Respir Crit Care Med 2016; 193: 178-185.

16 Kolb M, Richeldi L, Behr J, et al. Nintedanib in patients with idiopathic pulmonary fibrosis and preserved lung volume. Thorax 2017; 72: 340-346.

17 Maher TM, Flaherty KR, Inoue Y, et al. No effect of baseline diffusing capacity of lung for carbon monoxide on benefit of nintedanib. Eur Respir J 2016; 48: Suppl. 60, OA4959.

18 Raghu G, Wells AU, Nicholson AG, et al. Effect of nintedanib in subgroups of idiopathic pulmonary fibrosis by diagnostic criteria. Am J Respir Crit Care Med 2017; 195: 78-85.

19 Case AH, Capapey J, Kimura T, et al. Consistent effect of nintedanib on reducing FVC decline in patients with or without honeycombing in the INPULSIS ${ }^{\star}$ trials of idiopathic pulmonary fibrosis. Chest 2015; 148: Suppl., 361A.

20 Bonella F, Stowasser S, Wollin L. Idiopathic pulmonary fibrosis: current treatment options and critical appraisal of nintedanib. Drug Des Devel Ther 2015; 9: 6407-6419.

21 Schmidt SL, Tayob N, Han MK, et al. Predicting pulmonary fibrosis disease course from past trends in pulmonary function. Chest 2014; 145: 579-585.

22 Bellaye PS, Kolb M. Why do patients get idiopathic pulmonary fibrosis? Current concepts in the pathogenesis of pulmonary fibrosis. BMC Med 2015; 13: 176.

23 Ley B, Bradford WZ, Vittinghoff E, et al. Predictors of mortality poorly predict common measures of disease progression in idiopathic pulmonary fibrosis. Am J Respir Crit Care Med 2016; 194: 711-718.

24 Richeldi L, Azuma A, Selman M, et al. Twenty-four week decline in forced vital capacity (FVC) predicts mortality at week 52 in the INPULSIS ${ }^{\circledR}$ trials. Eur Respir J 2016; 48: Suppl. 60, OA1814.

25 Russell AM, Adamali H, Molyneaux PL, et al. Daily home spirometry: an effective tool for detecting progression in idiopathic pulmonary fibrosis. Am J Respir Crit Care Med 2016; 194: 989-997.

26 Johannson KA, Vittinghoff E, Morisset J, et al. Home monitoring improves endpoint efficiency in idiopathic pulmonary fibrosis. Eur Respir J 2017; 50: 1602406

27 Swigris JJ, Brown KK, Behr J, et al. The SF-36 and SGRQ: validity and first look at minimum important differences in IPF. Respir Med 2010; 104: 296-304.

28 Swigris JJ, Esser D, Conoscenti CS, et al. The psychometric properties of the St George's Respiratory Questionnaire (SGRQ) in patients with idiopathic pulmonary fibrosis: a literature review. Health Qual Life Outcomes 2014; 12: 124

29 Swigris JJ, Esser D, Wilson H, et al. Psychometric properties of the St George's Respiratory Questionnaire in patients with idiopathic pulmonary fibrosis. Eur Respir J 2017; 49: 1601788.

30 Swigris JJ, Wilson H, Esser D, et al. Psychometric properties of the St. George's Respiratory Questionnaire in patients with idiopathic pulmonary fibrosis: insights from the INPULSIS ${ }^{\circ}$ trials. BMJ Open Respir Res 2018; 5: e000278. 
31 Kreuter M, Stansen W, Stowasser S, et al. Impact of lung function decline on health-related quality of life in patients with idiopathic pulmonary fibrosis. Am J Respir Crit Care Med 2018; 197: Al604.

32 Hostettler KE, Zhong J, Papakonstantinou E, et al. Anti-fibrotic effects of nintedanib in lung fibroblasts derived from patients with idiopathic pulmonary fibrosis. Respir Res 2014; 15: 157.

33 Ackermann M, Kim YO, Wagner WL, et al. Effects of nintedanib on the microvascular architecture in a lung fibrosis model. Angiogenesis 2017; 20: 359-372. 